\title{
Práticas Discursivas e Produção de Sentidos nos Estudos Organizacionais: a Contribuição do Construcionismo Social
}

\author{
Alexandre Reis Rosa \\ Mestrando em Administração pelo Programa de Pós-graduação \\ em Administração da Universidade Federal de Lauras \\ (PPGA/UFLA) e Bolsista da CAPES \\ alexandrereisrosa@hotmail.com \\ César Tureta \\ Mestrando em Administração pelo Programa de Pós-graduação \\ em Administração da Universidade Federal de Lavras \\ (PPGA/UFLA) e Bolsista da CAPES \\ cesartureta@yahoo.com.br \\ Mozar José de Brito \\ Doutor em Administração pela FEA/USP e Coordenador \\ do Programa de Pós-graduação em Administração \\ da Universidade Federal de Lavras (PPGA/UFLA). \\ mozarjdb@ufla.br
}

\section{RESUMO}

Tendo o paradigma interpretativo como ponto de partida e o caráter interdisciplinar que vem permeando os estudos organizacionais nos últimos anos, o presente ensaio tem por objetivo explorar, no âmbito da psicologia social, uma proposta teórico-metodológica para o estudo da produção de sentidos no cotidiano. A partir de práticas discursivas, busca também situar a produção de sentidos junto ao movimento do construcionismo social que, alinhando ao debate pós-modernista, adota uma postura de ruptura com o modo tradicional de fazer ciência e busca ultrapassar a dualidade sujeito-objeto situando o conhecimento no interior dos processos de interação social. Embora o texto enfatize a perspectiva da psicologia social, a produção de sentidos é necessariamente interdisciplinar. O que torna possível a ponte com a ciência da administração e, conseqüentemente, uma possível incorporação de seus pressupostos à análise organizacional.

Palavras-chave: Construcionismo social, estudos organizacionais, pós-modernismo, produção de sentidos, práticas discursivas.

\section{ABSTRACT}

From the interpretative paradigm and the interdisciplinary character that it comes permeating the organization studies in the last years, this paper has the objective to explore, in the scope of social psychology, a proposal theoretical-methodological for the study of the making sense in the daily. Based on discursive practices, it also try to establish the making sense in the same place to the social constructionism movement that, aligned to the postmodernist debate, follow a rupture position with the traditional way to make science and try to overcome the duality subject-object, pointing out the knowledge in the interaction social processes. Although the paper emphasizes the social psychology perspective, the making sense is necessarily an interdisciplinary approach, which allows joining it with the science of management and, consequently, a possible incorporation of its assumptions to the organizational analysis.

Key Words: Social Constructionism, organization studies, postmodernism, making sense, discursive practices. 


\section{INTRODUÇÃO}

Embora hoje a produção científica no campo organizacional já disponha de uma abordagem multiparadigmática (HASSARD, 1993), ainda é comum a classificação paradigmática como forma de se identificar determinada pesquisa segundo o quadro de referência utilizado. Seja ela quantitativa ou qualitativa, há uma preocupação por parte dos pesquisadores em se manter uma coerência epistemológica nas discussões, alinhando paradigma, teoria e método. No entanto, como observa Morgan (1990), esta multiplicidade de opções teóricas veio à tona nos estudos organizacionais somente a partir da abertura da "caixa de pandora" com a publicação do polêmico livro Sociological Paradigms and Organizational Analysis em 1979 por Gibson Burrel e Gareth Morgan, cuja proposta foi a de romper com a ortodoxia ressaltando a diversidade de opções teóricas para a pesquisa organizacional.

Todavia, a discussão em torno dos paradigmas teóricos teve sua origem na publicação do livro de Thomas Kuhn "A estrutura das revoluções científicas" em 1962, onde muitos pesquisadores passaram a ver suas disciplinas de forma paradigmática. Nessa perspectiva, os teóricos organizacionais buscaram estabilizar o campo delimitando-o em quatro paradigmas "mutuamente excludentes": o Humanista Radical, o Estruturalista Radical, o Interpretativo e o Funcionalista (BURREL, 1998). O caráter excludente dos paradigmas foi o maior alvo de críticas. Isto é, o isolamento de cada paradigma impediu as chamadas conversações e ao mesmo tempo salvaguardou os paradigmas alternativos de serem dominados pelo mainstream representado pelo funcionalismo.

Partindo do conceito de paradigma como uma completa visão da realidade, ou seja, um modo de ver o mundo que se relaciona à organização social da ciência em termos de escolas de pensamento ligadas a tipos particulares de realizações científicas, pode-se dizer que o trabalho de Burrel e Morgan teve seu impacto e lançou novas luzes na análise organizacional. Pois ao ampliar o escopo de análise, “[...] forneceu as condições para que alguns analistas organizacionais abraçassem outros quadros de referência, sem se preocuparem demais com a ortodoxia" (BURREL, 1998, p.450). Nesse sentido, a multiplicidade paradigmática possibilitou a emergência de algumas fissuras no âmago dos estudos organizacionais e abordagens do tipo interpretativas ganharam espaço nas pesquisas.

Segundo Morgan (1980; 1990), a visão de mundo a partir do paradigma interpretativo entende que a realidade social não existe em qualquer sentido concreto, mas é um produto da experiência subjetiva e intersubjetiva dos indivíduos. Busca compreender a dinâmica da esfera social a partir da visão dos atores envolvidos no processo. Assim, a proposta deste paradigma é compreender o mundo a partir da experiência subjetiva dos indivíduos, considerando ainda a existência de uma tendência para o estabelecimento de uma ordem em questões sociais. Sua abordagem metodológica parte da compreensão dos fenômenos organizacionais respeitando a lógica inserida na própria dinâmica da organização analisada e busca entender o sentido que ela atribui ao fenômeno. Dessa forma, abriga escolas de pensamento tais como a hermenêutica, a fenomenológica, a interacionista simbólica e a etnometodológica e faz uso de ferramentas e textos específicos relacionados a jogos de linguagem e produção de sentidos.

Tendo, portanto, o paradigma interpretativo como ponto de partida e o caráter interdisciplinar que vem permeando os estudos organizacionais nos últimos anos, o presente ensaio tem por objetivo explorar, no âmbito da Psicologia Social, uma proposta teórico-metodológica para o estudo da produção de sentidos no cotidiano. A partir de práticas discursivas, busca também situar a produção de sentidos junto ao movimento do construcionismo social que, alinhando ao debate pós-modernista, adota uma postura de ruptura com o modo tradicional de fazer ciência e busca ultrapassar a dualidade sujeito-objeto situando o conhecimento no interior dos processos de interação social. Dessa forma, tende a se alinhar com os estudos organizacionais pós-modernos que surgem no âmbito do movimento anglosaxão denominado Estudos Críticos em Administração (ECA) cujo pressuposto básico é uma ruptura com o mainstream e a adoção de perspectivas teóricas alternativas que sejam capazes explicarem o fenômeno organizacional sob outro prisma. Embora o texto enfatize a perspectiva da psicologia social, a produção de sentidos é necessariamente interdisciplinar. O que torna possível a ponte com a ciência da administração e, conseqüentemente, uma possível incorporação de seus pressupostos à análise organizacional.

Para tanto, o texto está dividido em três grandes partes: a primeira mostra a evolução do construcionismo social e suas afiliações teóricas, com destaque para a psicologia social, bem como suas principais características e limitações teóricas; na segunda parte discute-se a produção de sentidos a partir de praticas discursivas, bem como sua relação com a linguagem e a história na construção e re-significação dos repertórios interpretativos; em seguida, a terceira parte busca estabelecer uma ponte da produção de sentidos com a pesquisa organizacional tendo como elo o movimento dos ECA e, finalmente, uma conclusão onde se resgata os pontos principais do texto e abrem-se algumas sugestões de pesquisa a partir da abordagem apresentada.

\section{O MOVIMENTO DO CONSTRUCIONISMO SOCIAL}

Para entender o movimento construcionista, segundo Gergen (1985), é necessário estabelecer uma relação com suas tradições intelectuais rivais. Isso implica em retomar a 
antinomia exogênico-endogênico presente na história da teoria psicológica. Essa antinomia, por sua vez, pode ser amplamente identificada em termos de orientações ou modelos básicos de conhecimento. Isto é, se de um lado os empiristas lógicos do século XX que representam a perspectiva exogênica localizaram a fonte do conhecimento nos eventos do mundo real e o próprio conhecimento como cópia dos contornos desse mundo espelhando-o como ele é, por outro lado, os fenomenologistas, que representam a perspectiva endogênica, localizaram as origens do conhecimento como um processo interno ao organismo humano que abriga tendências inatas que possibilitam pensar, categorizar e processar informações. Pois, diferente da perspectiva do mundo em si, essas tendências são de importância capital na configuração do conhecimento (GERGEN, 1985).

Alguns esforços por parte da psicologia clássica foram em vão na tentativa de unir as duas perspectivas. $\mathrm{Na}$ verdade o que prevaleceu foi o movimento pendular que deslocava a origem do conhecimento ora para o mundo externo, ora para o interno. Como exemplo disso, Gergen (1985) destaca o caso da psicologia desenvolvida nos EUA sob a influência da filosofia pragmatista e do positivismo que lhe deram um forte viés exogênico. Por meio do movimento behaviorista a atividade humana era ligada ao ambiente e o conhecimento, por extensão, era um reflexo adequado aos estímulos desse ambiente. Assim, a perspectiva endogênica acabou ficando em segundo plano diante da força do behaviorismo na psicologia americana.

A volta do pêndulo na direção da perspectiva endogênica veio com a importante reação do movimento cognitivista a partir das sementes da psicologia social plantadas por Kurt Lewin (GERGEN, 1985). O foco deixa de ser no ambiente e passa a depender do processamento de informações do mundo como é conhecido e não como ele é. Restituindo assim, o conceito de realidade social no lugar de realidade física. Ganham ênfase também os conceitos de processo de comparação social, percepção motivada e dissonância cognitiva.

Embora o movimento cognitivista tenha recuperado a perspectiva endogênica e dado suporte à emergência da psicologia social, bem como influenciado também a psicologia em geral, ainda assim não foi suficiente para superar a perspectiva exogênica. Pois, segundo Gergen (1985), tal superação nem poderá ocorrer uma vez que a própria base meta-teórica da ciência é de caráter exogênico e a concepção contemporânea da ciência psicológica é um subproduto da filosofia empirista que está intimamente comprometida em gerar um conhecimento objetivo do mundo. Assim, ao utilizar métodos para estabelecer esse tipo de conhecimento a partir dos próprios processos cognitivos e ao afirmar uma representação acurada do mundo, o psicólogo experimental contrapõe-se à opinião do mundo como é conhecido e corrobora a visão do mundo em si mesmo. Ao buscar uma verdade objetiva, o pesquisador cognitivista denigre a importância dos mesmos processos que tenta elucidar e a base exogênica da atividade científica acaba minando a validade das teorias endogênicas deslocando novamente o foco do interno para o externo (GERGEN, 1985).

Dessa forma, o movimento pendular que caracteriza a antinomia apresentada parece não ter solução. As disputas contínuas e não resolvidas entre pensadores exogênicos (empiristas) e endogênicos (fenomenológicos) demonstram uma incapacidade das teorias de resolver o dilema cartesiano de explicar como a matéria mental pode influenciar ou ditar diferentes movimentos corporais. Assim, ao invés de uma vez mais retomar o movimento de pêndulo, o construcionismo social se propõe ao desafio de transcender o dualismo tradicional sujeito-objeto a partir de uma nova estrutura de análise baseada numa teoria alternativa (não empirista) do funcionamento e dos potenciais da ciência. Este movimento, segundo Gergen (1985), inicia-se efetivamente quando se questiona o conceito de conhecimento como representação mental e se adota a visão de que o conhecimento não é algo que as pessoas possuem em algum lugar dentro da cabeça, mas sim algo que as pessoas fazem juntas através de práticas lingüísticas que são essencialmente atividades compartilhadas.

Para Íñiguez (2002), outros elementos diferenciam a postura construcionista das perspectivas antinômicas apontadas por Gergen (1985). O primeiro é o anti-essencialismo, ou seja, adota uma visão de que nem os sujeitos e nem o mundo têm uma natureza determinada; o segundo é anti-realismo, ou seja, a crença de que a construção coletiva gera a realidade e suas versões; o terceiro e quarto elemento são a especificidade histórica do conhecimento e a consideração da linguagem como uma condição prévia ao pensamento. Quanto à especificidade histórica, Ibáñez (1993) ressalta que o conhecimento seria produto de um processo de interação historicamente situado, pois tanto o sujeito como o objeto são construções sócio-históricas que precisam ser problematizados e desfamiliarizados, reconstruindo a noção de realidade.

Nesse contexto, torna-se também importante ressaltar que o conceito de construcionismo tem sido muitas vezes confundido com o de construtivismo. Embora ambos os movimentos teóricos sejam classificados como pós-modernos, caminham em direções opostas. Segundo Arendt (2003), ao passo que o construtivismo é oriundo da psicologia do desenvolvimento e busca dar conta da construção de estruturas cognitivas que o indivíduo elabora no decorrer do seu desenvolvimento, o construcionismo advém da psicologia social e busca dar conta das construções que os indivíduos elaboram coletivamente. Assim, observa-se que o foco do primeiro é individual e do segundo é social. Não obstante o ponto de encontro entre as duas perspectivas na crítica as grandes dicotomias (interno/externo, sujeito/objeto) que caracterizam o projeto modernista, destaca-se aqui 
a ênfase no construcionismo como forma de demonstrar sua flagrante vinculação com o conceito de construção social da realidade, tal como descrito pela sociologia do conhecimento que se constitui numa das afiliações teóricas deste movimento (GERGEN, 1985).

Nesta ótica, Spink e Frezza (2004) mostram que o construcionismo deriva de três movimentos interdependentes: a Filosofia, a Sociologia do Conhecimento e a Política. Por uma questão de escopo, focalizam o construcionismo a partir da Psicologia Social e da Sociologia do conhecimento. Nesta última, conforme o parágrafo anterior, há uma vinculação que é tratada por Berger e Luckmann (1985) em $A$ construção social da realidade. Neste livro, os autores vêem a realidade como socialmente construída não mais a partir do mundo das idéias que é de domínio dos homens sábios, mas sim, do senso comum que é de domínio do povo. Pois entendem que é este 'conhecimento' que efetivamente constitui o tecido de significados que caracterizam uma sociedade. Com efeito, afirmam que os significados subjetivos se tornam facticidades objetivas a partir de três conceitos centrais: a tipificação, a institucionalização e a socialização. $O$ ser humano passa a ser um "produto social" imerso numa dinâmica de conservação e ruptura que moldam a realidade e possibilitam a ressignificação e a transformação social.

A segunda vertente delimitada por Spink e Frezza (2004) é da própria psicologia social. Nela, as autoras mostram que, diferente da sociologia do conhecimento que privilegia os processos de conservação e transformação social, o foco da discussão reside justamente no momento da interação, nos processos de produção de sentido na vida cotidiana. Ou seja, como as pessoas descrevem e dão conta da realidade. Dessa forma, deslocam o locus da explicação do interno para o externo dando ênfase aos processos e estruturas da interação humana. No entanto, chamam a atenção para a necessidade de uma "desfamiliarização" das idéias preconcebidas na nossa percepção como condição prévia à adoção plena da perspectiva construcionista. Tais idéias - que estão no cerne da ciência modernista - passam pela crença na dualidade sujeitoobjeto, na concepção representacionista do conhecimento, na retórica da verdade e na concepção do cérebro como instância produtora do conhecimento. Ao abdicar destas quatro temáticas e entender o pensamento e o conhecimento como fenômenos sociais, podem-se eliminar as principais barreiras expressas pelo internalismo, essencialismo e universalismo que impedem a adesão plena da perspectiva construcionista e da compreensão do significado a partir das práticas discursivas.

\section{PRÁTICAS DISCURSIVAS E ANÁLISE DE DISCURSO}

A realidade das pessoas representada na vida cotidiana está permeada por símbolos e, quando diante deles, o processo de interpretação se desdobra. A Análise do Discurso permite uma relação mais próxima com a linguagem, uma vez que o discurso é a prática da linguagem e concebea como a intermediação entre o homem e a realidade social. Desde a antiguidade vários estudos foram realizados, embora não sistematizados, sobre a linguagem e sua produção de sentidos, o que é de interesse direto da Análise do Discurso. No entanto, somente nos anos 1960 que a Análise do Discurso ganha força com a lingüística, o marxismo e a psicanálise, mas não fica preso nestes campos do conhecimento, indo bem além de suas fronteiras (ORLANDI, 2003).

O termo análise de discurso, invariavelmente, é identificado como um método introduzido por Michel Pêcheux. Para este autor as condições da produção bem como um dado sistema lingüístico determinam o discurso. As práticas discursivas são consideradas o ponto central de análise na abordagem construcionista, implicando em ações, seleções e escolhas de várias produções sociais e fornecendo caminhos valiosos para o entendimento da produção de sentidos no cotidiano (SPINK e FREZZA, 2004). A análise do discurso não se reduz apenas à transmissão de informação e muito menos pode ser assinalada como linear, pois busca desvendar como objetos simbólicos produzem sentidos, considerando o universo de significações e inserindo assim o elemento interpretativo, porém, não se atendo estritamente a ele, dado que procura lidar com seus limites sem estabelecer um sentido verdadeiro através da interpretação (ORLANDI, 2003).

A análise, portanto, perpassa primeiro por uma etapa de apreciação do objeto e de construção dos sentidos no texto, para em seguida, imergindo profundamente no conteúdo, transpassar os esforços para o processo discursivo, em que surge a figura da ideologia, que está determinada por um contexto e grupo social de uma dada época. Aqui, a demanda é pela compreensão dos processos de significação que ocorrem no texto e estão relacionados à historicidade, ou seja, como as formações discursivas são construídas e sua relação com a ideologia. O que interessa no texto são aqueles elementos que forneçam subsídios para visualizar a ordenação por meio do qual se processa a materialização do discurso propriamente dito, permitindo o acesso do que não foi dito expressamente na fala, mas que, embora ocupe posição periférica no texto, é componente importante para o desdobramento da produção dos sentidos nele contidos. $\mathrm{O}$ subentendido e o pressuposto (tudo aquilo que está implícito no texto) também fazem parte do processo de análise, complementando o conteúdo que foi dito. A ausência das palavras (silêncio) ou seu lado oculto, não visível superficialmente, constituem expressões do discurso que podem revelar muito além do dizer explícito, carregando consigo significações historicamente produzidas (ORLANDI, 2003).

Vale lembrar, que o termo discurso é caracterizado por uma grande ambigüidade devido aos seus diversos usos, desenvolvimentos e perspectivas nas mais variadas disciplinas, 
como também dentro de uma mesma disciplina (TRAVERSOYÉPEZ, 1999). Neste sentido, Spink e Medrado (2004) fazem uma distinção entre discurso e práticas discursivas.

O discurso refere-se às regularidades lingüísticas ou à utilização institucionalizada da linguagem, que por sua vez ocorre no nível macro dos sistemas políticos e disciplinares e também num nível mais restrito que seria aquele onde se encontram os grupos sociais. Embora o contexto histórico tenha a capacidade de alterar os discursos, uma vez institucionalizado, eles tendem a permanecer no tempo (SPINK e MEDRADO, 2004). O discurso, porém, está repleto por tensões causadas entre o mesmo (processos parafrásticos) que desenvolve formulações diferentes para o mesmo dizer e o diferente (processo polissêmicos) que rompe com os processos de significação. A idéia central aqui é entender que o discurso está em constante construção, não se apresentando de maneira pronta. Ele se relaciona com outros e é sustentado por estes, não havendo delimitação de início e fim para o discurso (ORLANDI, 2003).

Essa dinâmica é conhecida como relação de sentidos e representa um dos fatores pelos quais as condições de produção funcionam. Um outro fator é a antecipação, ou seja, a inversão de posição, em que o locutor se coloca no lugar do interlocutor a fim de antecipar uma possível interpretação que este faria dos sentidos que suas palavras poderiam produzir, acarretando ajustes no modo como o locutor formatará sua argumentação (ORLANDI, 2003). Traverso-Yépez (1999), por sua vez, aborda esta questão sob a visão de reflexividade, que seria a capacidade de previsão da reação do outro. Nas relações de força, o lugar ocupado pelo sujeito no momento da fala afeta o significado de suas palavras. E por último, existem as formações imaginárias, responsáveis pela criação de imagens do sujeito ou representações do que o outro seja.

Os discursos aproximam-se da noção de linguagens sociais, definidas por Bakthin citado por Spink e Medrado (2004) como discursos de caráter particular a um estrato específico da sociedade e que emergem num dado contexto e momento histórico. O contexto, a circunstância, os interlocutores, o espaço, todos estes elementos influenciam diretamente na formatação e no estilo das enunciações, ou seja, os speech genres (gêneros de fala). Na visão daquele autor os gêneros de fala "são as formas mais ou menos estáveis de enunciados, que buscam coerência com o contexto, o tempo e o(s) interlocutores" (SPINK e MEDRADO, 2004, p.44).

Tomando o discurso como algo construído permanentemente, tem-se que a formação discursiva é constituída por ideologias - entendido aqui como a concepção de mundo, crenças e valores morais que se manifestam em todas as esferas da vida -, ou mais precisamente, pelas posições assumidas dentro de um determinado contexto sócio-histórico e que dão sentido às palavras. Uma mesma palavra, então, pode possuir diferentes significados quando se inserem em formações discursivas diferentes. Isso quer dizer que, dependendo da ideologia por trás da palavra contextualizada, das condições de produção e de um possível emprego metafórico, distintos significados podem emergir de uma única palavra (ORLANDI, 2003).

A produção do significado traz a relação com o outro como um fundamento da vida. A teoria relacional da construção do significado implica diretamente na produção do eu ou na produção do self. Sob a ótica construcionista, o self existe no interior das pessoas como um fenômeno narrativo e não como algo estável e duradouro, fazendo com que ele passe a ser entendido como um discurso presente nos contextos relacionais, ou seja, algo construído nos relacionamentos. A visão relacional do self constituído na linguagem retira do indivíduo a autoria única da construção de si mesmo e passa a entendê-lo a partir da construção social de múltiplos atores, uma vez que a narrativa sobre si mesmo remete a inúmeras vozes. Colocando de outra forma, "uma identidade nunca é individual, mas [sim] dependente de um conjunto de relacionamentos" (RASERA e JAPUR, 2001, p.204).

A explicitada co-autoria na produção do self está muito próxima do conceito de posicionamento, que ressalta o modo que o self é produzido discursivamente. Nesta linha de raciocínio, "um indivíduo emerge através dos processos de interação social, não como um produto final relativamente fixo, mas como alguém, que é constituído e reconstituído através das práticas discursivas nas quais participa" (DAVIES e HARRÉ citado por RASERA e JAPUR, 2001, p.204). Existe, portanto, uma multiplicidade de selves articulados em cada momento de acordo com a demanda de um diálogo.

No jogo das relações sociais, segundo Spink e Medrado (2004), as pessoas estão inseridas num contínuo processo de negociação, desenvolvido a partir de trocas simbólicas, num espaço de interpessoalidade. Desta forma, ao tomar as práticas discursivas como processo de interanimação dialógica, chegase ao conceito de posicionamento. Fixar uma posição significa transitar por múltiplas narrativas que possuímos contato e que se articulam nas práticas discursivas. Uma mesma pessoa pode se descrever e enfatizar determinados aspectos característicos de sua personalidade e de sua vivência, omitindo outros, levando em conta a situação, os interlocutores presentes e o contexto no qual está inserida naquele momento específico.

Já o conceito de práticas discursivas remete aos momentos de ressignificações e de produção de sentidos, correspondendo aos momentos ativos do uso da linguagem. As práticas discursivas são definidas como linguagem em ação, significando a forma com a qual as pessoas produzem sentidos e tomam posições nas relações cotidianas. Possui como elementos a dinâmica (enunciados orientados por vozes), as formas (speech genres) conceituadas anteriormente e os conteúdos (repertórios interpretativos).

$\mathrm{Na}$ perspectiva de Bakthin (1994), os conceitos de enunciados e vozes descrevem o processo de interanimação 
dialógica que se processa numa conversação. Os enunciados são as expressões articuladas em ações, emitidos no contato com uma ou mais pessoas num sentido mútuo de interação. Os enunciados começam a ganhar significado quando outros adicionam alguma forma de ação suplementar, lingüística ou não. As vozes representam todos aqueles interlocutores que dão vida e se fazem presentes nos diálogos correntes. São antecedentes aos enunciados e se manifestam e se processam no momento de sua produção.

Adicionalmente, Traverso-Yépez (1999) retrata o "outro" presente no discurso, não necessariamente representando um indivíduo, mas que pode se manifestar através de vozes que delineiam os enunciados por meio de expressões e valores retomados dos autores destas vozes. Assim, a compreensão dos sentidos está no confronto entre múltiplas vozes. O sentido, portanto, é oriundo do uso dos repertórios interpretativos que os indivíduos possuem. Os repertórios interpretativos, componentes fundamentais para o estudo das práticas discursivas, constituem as principais unidades de construção das práticas discursivas, isto é, são os termos, descrições e figuras de linguagem que delineiam as construções discursivas, tendo em vista o contexto de sua produção e os speech genres.

Seguindo o pensamento de Spink e Medrado (2004), a temporalidade dos repertórios mantém uma proximidade muito grande com a questão dos contextos dos sentidos. Isso significa dizer que o sentido contextualizado estabelece o diálogo permanente entre sentidos novos e antigos, em que estes últimos também são passíveis de renovação no desenrolar das trocas dialógicas. É nesta direção que existe uma necessidade de visualizar o contexto discursivo na interconexão de três tempos históricos:

(i) O Tempo Longo - são os conteúdos culturais que formam o discurso numa determinada época. É onde se apreende os repertórios disponíveis que serão formatados pelos aspectos circunstanciais de um dado período, constituindo as vozes manifestadas nos enunciados. O tempo longo é constituído por conhecimentos que antecedem a vivencia da pessoa, materializando-se nos mais diversos domínios do saber, tal como religião, ciência e tradições do senso comum.

(ii) O Tempo Vivido - pode ser entendido como a ressignificação dos conteúdos históricos a partir da socialização, isto é, está ligado às experiências adquiridas por uma pessoa ao longo de sua vivência pessoal. Neste nível incide o processo de aprendizagem das linguagens pessoais e dos comportamentos básicos do indivíduo.

(iii) O Tempo Curto - é tomado como o tempo do acontecimento, do momento presente e concreto da vida pessoal vista como de caráter interativo e que permite entender a produção dos sentidos. Esse caráter interativo refere-se às comunicações diretas (face a face) entre os interlocutores, pautado pela presença de variados repertórios que dão sentido às experiências pessoais de cada um.
Assim, tem-se na interface entre estes três tempos históricos a presença concomitante do novo e do velho, das permanências e rupturas, delimitando como a produção de sentidos se processa e como os sentidos circulam na sociedade.

\section{PRODUÇÃO DE SENTIDOS E LINGUAGEM}

Ao analisar um texto ou uma situação, os resultados gerados provavelmente serão diferentes de uma outra análise efetuada por um outro analista, ou até mesmo pelo mesmo analista, já que os conceitos empregados poderão e invariavelmente são diferentes. Se isso é verdade, é cabível distinguir dispositivo teórico da interpretação e dispositivo analítico concebido pelo analista. O dispositivo teórico refere-se aos conceitos utilizados para a interpretação de um fenômeno, enquanto o dispositivo analítico diz respeito aos procedimentos utilizados para a resolução de um problema. Contudo, cumpre ressaltar que ao analisar uma determinada situação, deve-se investigar além das evidências superficiais. Os sentidos não são encontrados somente nas palavras como mensagens a serem codificadas, mas possuem forte relação com o contexto ao seu redor, às condições nas quais são produzidos e mais ainda, refletem algo que não foi explicitamente dito ou que se encontra na "periferia" do conteúdo central. Sua parte subjetiva define as motivações e o conteúdo da fala do sujeito (ORLANDI, 2003).

Assim, é valido também dizer que as condições de produção (dos sentidos) abrangem o sujeito e a situação, além da memória como parte da produção do discurso. Num sentido mais restrito, essas condições se reduzem ao contexto imediato, mas quando ampliadas envolvem também o contexto sócio-histórico e ideológico. O contexto imediato está ligado àqueles elementos mais visíveis. Já o contexto amplo remete a elementos que transcendem a esfera visível que num primeiro momento não estariam "disponíveis" no contexto imediato. A história, outro componente relevante para a compreensão dos sentidos, mantém íntima relação com os acontecimentos que significam determinados símbolos utilizados para expressar uma idéia. A parte subjetiva do sentido define aquilo que o falante realmente quer expressar e os motivos que o conduzem a realizar dada emissão verbal (TRAVERSO-YÉPEZ, 1999).

A ruptura com o habitual permite dar maior visibilidade aos sentidos, sendo esta uma das principais estratégias da pesquisa social. De acordo com Spink e Medrado (2004), o sentido pode ser entendido como "[...] uma construção social, um empreendimento coletivo, mais precisamente interativo, por meio do qual as pessoas - na dinâmica das relações sociais historicamente datadas e culturalmente localizadas - constroem os termos a partir dos quais compreendem e lidam com as situações e fenômenos a sua volta (p. 41).

A memória, por fim, é tratada como interdiscurso ou mais precisamente aquilo que foi dito antes e em outro lu- 
gar. É a chamada memória discursiva: o saber discursivo que torna possível todo dizer e que retorna sob a forma do pré-construído, o já-dito que está na base do dizível, sustentando cada tomada da palavra. As experiências passadas são retomadas e os sentidos já ditos em algum momento anterior produzem efeito no discurso da fala corrente, ou seja, o já-dito possui uma relação com o que se está dizendo. Esta relação é a mesma existente entre interdiscurso e intradiscurso, ou de outra forma, entre constituição do sentido e formulação. A constituição seria o arcabouço repleto de dizeres já-ditos e esquecidos. A formulação é representada por aquilo que está sendo dito num certo momento e determinada pelo interdiscurso, que é a memória afetada pelo esquecimento (ORLANDI, 2003, p.31).

Cumpre ressaltar ainda que a produção de sentidos, tomada como um fenômeno sociolingüístico, não representa uma atividade cognitiva intraindividual, nem a simples reprodução de modelos predeterminados, mas sim se configura como uma prática social dialógica, que implica a linguagem em uso. A produção de sentidos é vista como tal fenômeno, pois a utilização da linguagem fornece sustentação às práticas sociais que geram sentidos e procura entender as práticas discursivas (narrativas, argumentações e conversas), assim como aqueles repertórios empregados nestas produções discursivas (SPINK e MEDRADO, 2004).

A significação da linguagem advém das formas através das quais funciona no interior de determinados padrões de relacionamentos, isto é, as palavras ganham significados a partir de seu uso social, das maneiras pelas quais são empregadas nos relacionamentos. A linguagem não possui apenas um papel reprodutivo, nem é simplesmente um reflexo da realidade, mas sim exerce uma função criativa ou de (re)interpretação da realidade (TRAVERSO-YÉPEZ, 1999).

A abordagem construcionista tem como um de seus direcionadores privilegiarem o estudo da linguagem enquanto algo constituinte de práticas sociais na investigação da produção do conhecimento, invertendo a lógica de enfocar apenas a mente individual, pois a linguagem é considerada uma atividade compartilhada e não isolada, sendo compreendida também como prática social (SPINK e MEDRADO, 2004). Por isso, sua análise precisa concentrar no relacionamento interpessoal e não individual, uma vez que é por meio da coordenação relacional que emerge a linguagem. Através dos momentos interativos entre as pessoas e de uma compreensão ativa é possível entender como as pessoas se constroem, num processo de conhecer e responder ativamente uma às outras (RASERA e JAPUR, 2001).

Uma corrente analítica da perspectiva lingüística empregada na Psicologia Social de cunho construcionista merece destaque: as trocas lingüísticas. Em seu trabalho, Spink e Frezza (2004) fazem menção a um artigo de Jerome Bruner (1984), no qual este autor propõe que o foco nas trocas lingüísticas sugere três critérios de análise da linguagem: (i) Foco na boa formatação - a questão aqui é saber o quão bem elaborados são os enunciados no que se refere às regras gramaticais existentes na linguagem. Trata-se, portanto, da esfera da sintaxe, que procura compreender o sentido dos enunciados ou o emprego que deles é feito.

(ii) Foco no sentido - um enunciado está relacionado a algo num mundo real ou em um mundo possível, e tem um sentido. Aqui, faz-se referência à esfera semântica, cuja análise refere-se aos significados.

(iii) Foco na performática - este foco trata de quando, em que condições, com que intenção e de que modo devemos falar. Representa a esfera da pragmática da linguagem, isto é, as condições de uso dos enunciados.

De acordo com Spink e Frezza (2004), além deste trabalho existem ainda duas outras corrente importantes centradas na linguagem em uso: a etnometodologia e a análise de conversação. Por não influenciarem diretamente na presente discussão e por limitações de espaço, estas duas correntes não serão tratados neste ensaio.

\section{CRÍTICAS AO CONSTRUCIONISMO SOCIAL}

A principal crítica ao construcionismo social refere-se à forma de encarar o processo de construção, considerando-o como resultado consciente do processo de interação. A construção social da realidade tem sido descrita de maneira simplificada por várias pesquisas, chegando ao nível da ingenuidade. Ademais, outro ponto crítico é que o emprego do construcionismo social também tem gerado um reducionismo da análise. Fundamentado em algumas pesquisas de campo, Bruno Latour (2005) oferece contribuições no que tange às críticas endereçadas ao construcionismo social. Este autor critica o atual uso do construcionismo social, identificando o adjetivo "social" como uma de suas falhas, pois a utilização deste termo incorre em acreditar que a construção é quase sempre realizada pelo agente humano, tido como um ser que comanda e domina o mundo com suas construções e intenções. Portanto, não se deve negligenciar que a sociedade é constituída por humanos e não humanos, e os mesmos nunca estão dissociados, pois cada ação que executamos está ligada, ou é mediada por não humanos. Desta forma, para que haja estabelecimento do equilíbrio faz-se necessário balancear as análises da sociedade, considerando tanto a dimensão humana quanto a não humana (PECI e ALCADIPANI, 2004).

Essa problemática, na visão dos autores supracitados, se remete igualmente às divisões existentes entre pequeno/ grande, contexto/conteúdo, agência/estrutura, dentre outros. Adelbert Jenkins citado por Stam (2001) oferece uma crítica semelhante quando salienta o equívoco do construcionismo social em distinguir conteúdo de processo. De acordo com este autor o conteúdo do self difere radicalmente em função da cultura, no entanto, o processo gerado 
e mantido pelo self é universal. Logo, a noção do self e do "outro" são criados e sustentados mutuamente (STAM, 2001). Partindo de tais críticas, é interessante observar que a materialidade se faz presente tanto quanto a agência no processo de construção, dado que humanos e não humanos possuem capacidades de executar ações, sendo que estes últimos, muitas vezes, incorporam características dos primeiros (PECI e ALCADIPANI, 2004).

Na visão de Spink e Frezza (2004) a perspectiva construcionista do conhecimento tende a ser contestada especialmente por causa do relativismo e do reducionismo lingǘstico. No caso do relativismo, os críticos enfatizam o fato de que para o construcionismo toda crença em relação a um determinado tópico é igualmente aceitável. Já no que tange ao reducionismo lingüístico, a abordagem construcionista evidencia que algo conquista o caráter de objeto através do processo de construção lingüísticoconceitual, demonstrando assim a centralidade que o construcionismo confere à linguagem.

\section{A POSSIBILIDADE DE UM DIÁLOGO: O CONSTRUCIONISMO SOCIAL NOS ESTUDOS ORGANIZACIONAIS}

Falar em construcionismo social nos estudos organizacionais requer um esforço de abrir pontes de conversação entre as áreas. Sendo o construcionismo uma perspectiva alinhada ao movimento do pós-modernismo (ARENDT, 2003) e os estudos organizacionais terem recentemente aderido ao mesmo movimento por meio de uma perspectiva crítica de análise organizacional, pode-se pensar, portanto, numa possível conversação entre eles. No entanto, antes disso convém delimitar a vertente dos estudos críticos no âmbito dos estudos organizacionais.

Com a abertura paradigmática citada na introdução deste ensaio, outras abordagens teóricas começam a ganhar destaque nas pesquisas em administração. Novos autores foram incorporados ao debate e a dinâmica organizacional ganhou outros contornos. Dentro desta perspectiva, se insere - inicialmente na Europa e depois nos EUA - o movimento do Critical Management Studies ou, em tradução aproximada, Estudos Críticos em administração (ECA) que, segundo Fournier e Grey (2000), são caracterizados por três aspectos fundamentais:

(i) Visão desnaturalizada da administração. No processo de naturalização (processo ampla e vulgarmente utilizado pelas teorias tradicionais), a formação social é abstraída do contexto histórico e conflituoso de sua origem, sendo tratada como uma entidade concreta e relativamente fixa. Nos ECA, visa-se romper com esta lógica, propondo um questionamento sistemático deste edifício teórico e passando a considerar a organização como um resultado sócio-histórico, compreendendo sua formação, con- solidação e transformação a partir de uma realidade socialmente construída;

(ii) Intenções desvinculadas de desempenho. Outro ponto destacado nesta perspectiva é o fato de que tais estudos não buscam desenvolver conhecimentos que contribuam para a maximização de resultados. Ou seja, os ECA não visam celebrar conhecimentos inscritos em uma lógica instrumental de cálculo dos meios com relação aos fins ou que melhorem o desempenho econômico das organizações. Em uma perspectiva não crítica, a performance é o ponto central e todo conhecimento ou prática deve ser gerado sem jamais deixar espaço a questionamentos nem a dúvidas. $\mathrm{Na}$ abordagem crítica não existe esta preocupação, pois o foco está na tentativa de emancipar os homens dos mecanismos de opressão, tendo, de fato, o humano como ponto fundamental;

(iii) Busca de emancipação. Os ECA procuram expressar um interesse explícito pela abolição das injustiças, enfatizando e promovendo o potencial da consciência humana para refletir de maneira crítica sobre as práticas opressivas, facilitando, assim, a extensão dos níveis de autonomia e responsabilidade das pessoas. Por autonomia entende-se a capacidade dos seres humanos de produzir julgamentos que não sejam impedidos ou deformados por dependências sociais inúteis associadas à subordinação às desigualdades de riqueza, de poder e de conhecimento. Por responsabilidade entende-se o desenvolvimento de uma consciência de nossa interdependência social e, conseqüentemente, a compreensão de nossa responsabilidade coletiva para com os outros.

A base do movimento crítico, segundo Alvesson e Deetz (1998), reside nas contribuições advindas da Teoria Crítica e do Pós-Modernismo. Ambas as perspectivas são relativamente novas para os estudos de gestão, são em sua maioria de difícil leitura, cruzam muitas fronteiras disciplinares e compartilham - segundo alguns autores - de diferenças irreconciliáveis. Sua introdução nos estudos organizacionais foi tardia em relação a outras áreas do conhecimento. Pois a teoria crítica remonta do final dos anos 1970 e começo dos anos 1980, ao passo que o pós-modernismo do fim dos anos 1980. Tais correntes questionam os pressupostos do mainstream que eram - e de certa medida ainda continuam sendo - marcados por uma inclinação positivista ou marxista. A emergência dessas alternativas teóricas nos estudos organizacionais é o resultado de um declínio e desilusão com os pressupostos modernistas, tanto teóricos como práticos que norteiam o campo organizacional. Assim, o ataque à tradição modernista é o foco central destas novas perspectivas (ALVESSON e DEETZ, 1998).

A crise do discurso modernista tem sido evidenciada a partir do declínio das grandes narrativas e da crítica ao predomínio da racionalidade instrumental. Baseada no controle, na racionalização e na crescente colonização da natureza das pessoas enquanto trabalhadores, consumidores ou sociedade, a administração modernista tem gerado efeitos questionáveis em face de uma perspectiva crítica de análise. 
Temas como cultura organizacional, identidade, gestão da qualidade, gestão de serviços e um renovado apelo à liderança, alma e carisma no final dos anos 1980 e inicio dos 1990 ilustram isso. No entanto, como afirmam Alvesson e Deetz (1998), as evidências empíricas são altamente seletivas e fracas. Por isso, fala-se aqui em estudos críticos e pósmodernos e não em organizações críticas e pós-modernas.

Nesses estudos, dado o enorme leque de possibilidades, existem alguns recortes teóricos que delimitam a análise. No que se refere à teoria crítica, fala-se prioritariamente, mas não exclusivamente, nos conceitos advindos da Escola de Frankfurt em sua primeira e segunda geração. No que se refere ao pós-modernismo, o foco é sobre o conjunto de abordagens filosóficas para o estudo da organização e de outras áreas e sua ênfase passa pelos conceitos de fragmentação, textualidade e resistência. Ambas as perspectivas (crítica e pós-moderna) posicionam seus trabalhos em relação a quatro desenvolvimentos específicos do pensamento ocidental: a relação poder/conhecimento; a teoria de conflito social e historicamente embasada; o sujeito humano e complexo visto pela psicanálise e próprio construcionismo não dualista. A combinação da teoria crítica com o pós-modernismo visa estabelecer uma complementaridade que tenta responder ao modernismo destacando suas falhas e ressaltando suas virtudes, ao mesmo tempo em que busca abrir novas perspectivas de análise que rompam com a tradição teórica propagada pelo discurso dominante modernista.

No debate veiculado pelos ECA, o pós-modernismo tem lugar de destaque em relação à teoria crítica e é a partir dele que se pretende estabelecer a ponte com o movimento do construcionismo social. O leque de pesquisas é mais extenso e o número de abordagens maior ainda. Nesta perspectiva incluem-se estudos feministas, análise de discurso, actor-network theory, estética entre outros (pós-estruturalismo, pós-colonialismo, pós-marxismo etc.). Suas formulações perpassam múltiplos paradigmas o que torna sua abordagem imprecisa, confusa e em certa medida não-científica. $\mathrm{O}$ esforço de incluí-la nos estudos organizacionais passa necessariamente pela delimitação dos principais pontos que formam o conjunto de idéias inter-relacionadas presentes no debate organizacional.

Entre estes pontos, segundo Alvesson e Deetz (1998), estão: (i) A centralidade do discurso e sua textualidade como formas de construção da realidade e de constituição do sujeito a partir da linguagem; (ii) As identidades fragmentadas que negam o self unitário e considera o indivíduo como construção social atrelada a múltiplos discursos que tendem a se expandir inevitavelmente; (iii) A crítica da filosofia da presença e da representação que considera a existência de um objeto somente a partir da relação dele com um ser que o representa sempre de forma parcial; (iv) Crítica as grandes narrativas e aos movimentos fundamentalistas que buscam explicar de forma essencialista todos os fenômenos que na verdade são localmente situados; (v) Conexão poder/saber onde o primeiro está inserido no discurso que é sustentado por arranjos materiais que tiram a neutralidade do segundo e demonstra que ambos são faces da mesma moeda; (vi) Hiper-realidade que manipula a realidade a partir da simulação de imagens vão além da representação, mas que substituem o mundo; (vii) Estética organizacional em contraponto ao ideal modernista de racionalidade e empirismo como formas iluministas de fazer ciência; e (viii) Resistência teórica ao formato positivista de fazer ciência que domina e violenta o mundo limitando-se ao processo que de certa forma impõe suposições orientadoras e relações fixas.

Embora os ECA e próprio construcionismo adotem o conceito de pós-modernidade em sua abordagem, vale ressaltar que não existe um consenso sobre isso no âmbito das ciências sociais. Ou seja, na teoria social e na filosofia este debate ganha outros contornos. Segundo Lipovetski (2004), por exemplo, se o advento da modernidade for considerado a partir do tripé: mercado, indivíduo e escala técnico-científica, pode-se dizer que nos anos 1980 a globalização se encarregou de acirrá-los, mas não superá-los. Pois chegaram ao ponto de saturação onde seus pressupostos se apresentam de forma mais intensa e veloz que antes, mas não ao ponto de ruptura. Uma vez que ainda dispomos deles como pilares de sustentação da sociedade e, por extensão, das organizações. Assim, segundo o autor, a sociedade contemporânea vive uma espécie de hipermodernidade cuja lógica está justamente na intensidade e na velocidade com que o mundo hoje se apresenta e, consequentemente, no reflexo disso sobre o comportamento dos indivíduos. Não obstante a polêmica, considerando a perspectiva pós-moderna como ponto de encontro entre as abordagens, o construcionismo social - representado aqui pela corrente da psicologia social que enfatiza a produção de sentidos por meio de práticas discursivas - pode ser uma alternativa interessante para viabilizar estudos empíricos a partir da corrente de estudos críticos.

Com a passagem da evidência-baseada-na-autoridade para a evidência-das-coisas é aberto um espaço para novas formas de empirismo que geraram um novo conceito de evidência. Ou seja, a partir daí tem-se uma junção entre experimentação e leitura de signos numa produtiva combinação que o construcionismo, na hermenêutica moderna, conduz a uma interpretação inacabada em contraposição à velha dogmatização do critério de verdade única que ingenuamente buscavam uma única leitura dos fenômenos da existência (SPINK e LIMA, 2004). Assim, a interpretação é sempre a interpretação de alguém que na suspeita do que foi dito, vê inúmeras possibilidades de outros sentidos que estão por baixo do discurso.

No esforço de dar visibilidade, a interpretação é colocada como um processo de produção de sentidos que caracteriza o meio e o fim da tarefa de pesquisa. A partir dele são 
produzidos os resultados da análise que podem ser fruto de várias técnicas de visibilização que servem de estratégia para assegurar o rigor e, na medida do possível, a objetividade no âmbito da subjetividade gerada a partir dos repertórios interpretativos utilizados na compreensão dos sentidos. Entre as técnicas de visibilidade, Spink e Lima (2004) destacam os mapas de associação de idéias que sistematizam o processo de análise das práticas e buscam os aspectos formais da produção lingüística; as árvores de associação que complementam os mapas proporcionando mais um recurso para entender como um determinado argumento e construído e; finalmente as linhas narrativas que buscam, no conteúdo das histórias, situar as diversas nuanças presentes no discurso.

Tais recursos metodológicos são as características principais da investigação dos sentidos dentro da proposta teórico-metodológica de estudo da produção dos sentidos vinculada ao construcionismo social. No Brasil diversas pesquisas no âmbito da psicologia social têm sido realizadas a partir destes recursos (SPINK, 2004). Por outro lado, na área organizacional há uma ínfima quantidade de pesquisas nessa linha, com destaque para os trabalhos da Professora Maria José Tonelli da FGV-EAESP que tem desenvolvido uma série de pesquisa sobre o sentido do trabalho $(2000,2003)$ e do tempo (2000, 2002 e 2002a) nas organizações. Com isso, podese constatar o potencial ainda a ser explorado justificando a proposta deste trabalho de inserir no debate organizacional a perspectiva construcionista de investigação de sentidos.

\section{CONSIDERAÇÕES FINAIS}

Como foi apresentado, análises de tipo construcionista social têm se preocupado tipicamente com as formas de linguagem que permeiam a sociedade, os meios pelos quais são negociadas e suas implicações para outras gamas de atividades sociais. A partir dela, psicólogos sociais começam a se unir nesses esforços, assim como com os pesquisadores organizacionais que dentro de um paradigma interpretativo tem buscado dar conta principalmente dos sistemas humanos de significado. Isso sugere um amplo leque de opções tais como gênero, agressão, pessoa, self, motivação, emoção, moralidade, tempo, violência e assim por diante.

Pôde ser demonstrado também que a abordagem construcionista encontra-se com os estudos organizacionais na ponte estabelecida pelo movimento dos estudos críticos em administração que tem no pós-modernismo sua principal vertente de análise. Tal encontro possibilita duas potencialidades: a primeira é de consolidar estudos empíricos dentro da vertente crítica que ainda constitui-se num ponto falho desta abordagem (ALVESSON e WILLMOTT, 1993; ALVESSON e DEETZ, 1998; FOURNIER e GREY, 2000); a segunda é trazer da psicologia social a proposta teóricometodológica de estudo das praticas discursivas para o am- biente emblemático das organizações que hoje, mais do que nunca, são o locus principal das principais patologias contemporâneas relacionadas ao mundo do trabalho.

Finalmente, vale destacar que o valioso arcabouço de análise proporcionado pela proposta teórico-metodológica de estudo da produção dos sentidos a partir do construcionismo social ajuda os analistas organizacionais a compreender melhor as obscuras questões ligadas ao poder, ao gênero e a violência no trabalho. Uma vez que, boa parte dessas questões passa pela postura dos atores na prática dialógica e, conseqüentemente, na construção e afirmação de práticas discursivas frente aos constrangimentos estruturais que habitam o universo organizacional.

\section{REFERÊNCIAS BIBLIOGRÁFICAS}

ALVESSON, M.; DEETZ, S. Teoria crítica e abordagens pósmodernas para os estudos organizacionais. In: CLEGG, Stewart R. et al. (Orgs.) Handbook de Estudos Organizacionais: modelos de análise e novas questões em estudo organizacionais. v.1. São Paulo: Atlas, 1998.

ALVESSON, M.; WILLMOTT, H. (Eds.) Critical Management Studies. London: Sage, 1993.

ARENDT, R. J. Construtivismo ou construcionismo? Contribuições deste debate para a psicologia social. In: Estudos de Psicologia, 8 (1), 5-13, 2003.

BAKHTIN, M. The problems of speech genres. In: EMERSON, C.; HOLQUIST, M. (Orgs.) Speech genres and other late essays. Austin: University Texas Press, 1994.

BERGER, P. L.; LUCKMANN, T. A construção social da realidade: tratado de sociologia do conhecimento. $12^{\mathrm{a}} \mathrm{Ed}$. Petrópolis: Vozes, 1985.

BRUNER, J. Pragmatics of language and language of pragmatics. Social Research. v.51, n.4, p.969-984, 1984.

BURREL, G. Ciência normal, paradigmas, metáforas, discursos e genealogia de análise. In: CLEGG, Stewart R. et al. (Orgs.) Handbook de Estudos Organizacionais: modelos de análise e novas questões em estudo organizacionais. v.1. São Paulo: Atlas, 1998.

FOURNIER, V.; GREY, C. At the critical moment: conditions and prospects for critical management studies. Human Relations. v.53, n.1, p.7-32, 2000.

GERGEN, K. The social constructionist movement in modern psychology. In: American Psychology, 40 (3), p.266-275, 1985.

HASSARD, J. Sociology and Organization theory: positivism, paradigms and postmodernity. Cambridge: Cambridge University Press, 1993.

IBÁÑEZ, T. Construccionismo y psicologia. In: Revista Interamericana de Psicologia. v.28, n.1, p.105-123, 1993.

ÍÑIGUEZ, L. Construcionismo social e psicologia social. In: MARTINS, J. B. (Org.) Temas em análise institucional e em construcionismo social. São Carlos: RIMA, 2002. 
LATOUR, B. The promises of constructivism. Disponível em: < http:/ /www.ensmp.fr/ latour/articles/article/087.html>. Acesso em $18 / 09 / 2005$.

LIPOVETSKI, G. Os tempos hipermodernos. São Paulo: Barcarolla, 2004.

MINAYO, M. C. de S. Ciência, técnica e arte: o desafio da pesquisa social. In: MINAYO, Maria C. de S (Org.). Pesquisa social: teoria, método e criatividade. Petrópolis: Vozes, 2001.

MORGAN, G. Paradigms diversity in organizational research. In: HASSARD, J.; PYM, D. (Eds.). The theory and philosophy of organizations: Critical issues and new perspectives. London: Routledge, 1990.

MORGAN, G. Paradigms, metaphors, and puzzle solving In Organization theory. Administrative Science Quarterly, 25 (1), p.605$622,1980$.

ORLANDI, E. P. Análise de discurso: princípios e procedimentos. 5 Edição. Campinas: Pontes, 2003.

PECI, A.; ALCADIPANI, R. Demarcação científica: uma reflexão crítica. In: Encontro da associação nacional de pós-graduação em administração, 28, Curitiba. Anais... Curitiba: ANPAD, 2004. 1 CD-ROM.

RASERA, E. F.; JAPUR, M. Contribuições do pensamento construcionista para o estudo da prática grupal. In: Psicologia: reflexão e crítica. v. 14. n. 1. p. 201-209, 2001.

SPINK, M. J.; (Org.). Práticas discursivas e produção de sentidos no cotidiano. $3^{\text {a }}$ Ed. São Paulo: Cortez, 2004.

SPINK, M. J.; FREZZA, R. M. Práticas discursivas e produção de sentidos: a perspectiva da psicologia social. In: SPINK, M. J. (Org.). Práticas discursivas e produção dos sentidos no cotidiano: aproximacõos teóricas e metodológicas. 3. ed. São Paulo: Cortez, 2004.

SPINK, M. J.; LIMA, H. Rigor e visibilidade: a explicitação dos passos da interpretação. In: SPINK, M. J. (Org.). Práticas discursivas e produção dos sentidos no cotidiano: aproximações teóricas e metodológicas. 3. ed. São Paulo: Cortez, 2004.
SPINK, M. J.; MEDRADO, B. Produção de sentidos no cotidiano: uma abordagem teórico-metodológica para análise das práticas discursivas. In: SPINK, M. J. (Org.). Práticas discursivas e produção dos sentidos no cotidiano: aproximações teóricas e metodológicas. 3. ed. São Paulo: Cortez, 2004.

SPINK, P. K. Pesquisa de campo em psicologia social: uma perspectiva pós-construcionista. In: Psicologia \& Sociedade. v. 15. n. 2. p. 18-42. Jul./Dez., 2003.

STAM, H. J. Introduction: social constructionism and its critics. In: Theory \& Psychology. v. 11. n. 3. p. 291-296, 2001.

TONELLI, M. J. O Trabalho e seus Sentidos. In: encontro da associação nacional de pós-graduação em administração, 27, Atibaia. Anais... Atibaia: ANPAD, 2003. 1 CD-ROM.

TONELLI, M. J. Organizações pós-modernas: uma discussão sobre as novas competências requeridas aos gestores e a maquiagem do self. In: Encontro da associação nacional de pós-graduação em administração, 24, Florianópolis. Anais... Florianópolis: ANPAD, 2000. 1 CD-ROM.

TONELLI, M. J. Pós-Modernidade, teoria organizacional e o self do gerente minuto. In: Encontro de estudos organizacionais, 1., 2000, Anais... Curitiba: ANPAD, 2000. 1 CD-ROM.

TONELLI, M. J. Produção de sentidos: tempo e velocidade nas organizações. In: Encontro de estudos organizacionais, 2., 2002, Anais... Recife: Observatório da Realidade Organizacional: PROPAD/ UFPE: ANPAD, 2002. 1 CD-ROM.

TONELLI, M. J. Tempo é Dinheiro? A Construção do Tempo na Administração Contemporânea. In: Encontro da associação nacional de pós-graduação em administração, 26, Salvador. Anais... Salvador: ANPAD, 2002a. 1 CD-ROM.

TRAVERSO-YÉPEZ, M. Os discursos e a dimensão simbólica: uma forma de abordagem à Psicologia Social. In: Estudos de Psicologia, Natal, 1999, 394 (1), 39-59. 
Práticas discursivas e produção de sentidos nos estudos organizacionais: A contribuição do construcionismo social

52/ CONTEXTUS Revista Contemporânea de Economia e Gestão. Vol.4 - № 1 - jan/junn/2006 (41-52). 